\title{
ISL1 overexpression enhances the survival of transplanted human mesenchymal stem cells in a murine myocardial infarction model
}

Qiuling Xiang ${ }^{1,2+}$, Yan Liao ${ }^{1,2+}$, Hua Chao ${ }^{2 \dagger}$, Weijun Huang ${ }^{1,2}$, Jia Liü ${ }^{3}$, Haixuan Chen ${ }^{4}$, Dongxi Hong ${ }^{5}$, Zhengwei Zou ${ }^{1,2}$, Andy Peng Xiang ${ }^{1,2}$ and Weiqiang $\mathrm{Li}^{1,2^{*}}$

\begin{abstract}
Background: The LIM-homeobox transcription factor islet-1 (ISL1) has been proposed as a marker for cardiovascular progenitor cells. This study investigated whether forced expression of ISL1 in human mesenchymal stem cells (hMSCs) improves myocardial infarction (MI) treatment outcomes.

Methods: The lentiviral vector containing the human elongation factor 1a promoter, which drives the expression of ISL1 (EF1a-ISL1), was constructed using the Multisite Gateway System and used to transduce hMSCs. Flow cytometry, immunofluorescence, Western blotting, TUNEL assay, and RNA sequencing were performed to evaluate the function of ISL1-overexpressing hMSCs (ISL1-hMSCs).

Results: The in vivo results showed that transplantation of ISL1-hMSCs improved cardiac function in a rat model of MI. Left ventricle ejection fraction and fractional shortening were greater in post-MI hearts after 4 weeks of treatment with ISL1-hMSCs compared with control hMSCs or phosphate-buffered saline. We also found that ISL1 overexpression increased angiogenesis and decreased apoptosis and inflammation. The greater potential of ISL1-hMSCs may be attributable to an increased number of surviving cells after transplantation. Conditioned medium from ISL1-hMSCs decreased the apoptotic effect of $\mathrm{H}_{2} \mathrm{O}_{2}$ on the cardiomyocyte cell line $\mathrm{H} 9 \mathrm{c} 2$. To clarify the molecular basis of this finding, we employed RNA sequencing to compare the apoptotic-related gene expression profiles of control hMSCs and ISL1-hMSCs. The results showed that insulin-like growth factor binding protein 3 (IGFBP3) was the only gene in ISL1-hMSCs with a RPKM value higher than 100 and that the difference fold-change between ISL1-hMSCs and control hMSCs was greater than 3, suggesting that IGFBP3 might play an important role in the anti-apoptosis effect of ISL1-hMSCs through paracrine effects. Furthermore, the expression of IGFBP3 in the conditioned medium from ISL1-hMSCs was almost fourfold greater than that in conditioned medium from control hMSCs. Moreover, the IGFBP3 neutralization antibody reversed the apoptotic effect of ISL1-hMSCs-CM.
\end{abstract}

Conclusions: These results suggest that overexpression of ISL1 in hMSCs promotes cell survival in a model of MI and enhances their paracrine function to protect cardiomyocytes, which may be mediated through IGFBP3. ISL1 overexpression in hMSCs may represent a novel strategy for enhancing the effectiveness of stem cell therapy after MI.

Keywords: ISL1, Human mesenchymal stem cells, Survival, Myocardial infarction

\footnotetext{
*Correspondence: liweiq6@mail.sysu.edu.cn

${ }^{\dagger}$ Equal contributors

${ }^{1}$ Center for Stem Cell Biology and Tissue Engineering, Key Laboratory for

Stem Cells and Tissue Engineering, Ministry of Education, Sun Yat-sen

University, Guangzhou, People's Republic of China

'Zhongshan Medical School, Sun Yat-sen University, Guangzhou, People's

Republic of China

Full list of author information is available at the end of the article
} 


\section{Background}

Heart disease is a major cause of mortality and morbidity worldwide. Acute and chronic loss of cardiomyocytes is a main contributor to poor cardiac function that culminates in heart failure [1]. Investigators have long pursued strategies to replace lost heart muscle. One approach has been to isolate stem cells from bone marrow, blood, skeletal muscle, or fat and inject them into the damaged heart [2]. This strategy has been tested for safety and efficacy in animal models of myocardial infarction (MI) and humans. However, one of the major obstacles to using stem cells for therapy is the poor survival rate of transplanted stem cells in ischemic tissues due to the hypoxic environment [3]. Interestingly, Gnecchi et al. provided evidence that a combination of human mesenchymal stem cells (hMSCs) and AKT overexpression-based gene therapy enhanced cell survival, therapeutic neovascularization, myocardial protection, and functional improvement through paracrine mechanisms [4]. Another report showed that prolyl hydroxylase domain protein 2 (PHD2) silencing enhanced the survival and paracrine function of transplanted adipose-derived stem cells in infarcted myocardium [5].

The LIM-homeobox transcription factor islet-1 (ISL1) plays a crucial role during heart embryogenesis and later promotes the development of adult resident cardiac stem cells. One of the earliest steps in cardiogenesis is when the cells of the cardiogenic mesoderm form the cardiac crescent. ISL1 progenitors, which comprise the cardiac crescent, migrate into the developing heart and give rise to the outflow tract, right ventricle, and both atria $[6,7]$. ISL1 expression is then turned off except in a small population of resident cardiac stem cells which maintain ISL1 expression throughout adulthood [8]. Cagavi et al. described functional cardiomyocytes derived from ISL1 cardiac progenitors via bone morphogenetic protein stimulation, which could lead to enhancement of cardiac differentiation and engraftment [9]. Our previous work confirmed that ISL1 overexpression in hMSCs promotes vascularization through monocyte chemoattractant protein-3 [10]. However, whether ISL1 overexpression influences the effects of hMSC transplantation in infarcted myocardium remains unknown.

The purpose of this study was to test the hypothesis that ISL1 overexpression enhances stem cell survival and paracrine function after transplantation, thus enhancing protection and repair of the damaged heart. We constructed a lentivector for ISL1 overexpression under the control of the human elongation factor $1 \alpha(\mathrm{EF} 1 \alpha)$ promoter. This construct was used to generate ISL1-hMSCs, which were then injected into an MI model. The experiments performed showed that ISL1-hMSC administration improved cardiac function, and ISL1 overexpression enhanced cardioprotection by promoting hMSC survival in
MI and enhancing their paracrine function, which may be mediated through insulin-like growth factor binding protein 3 (IGFBP3).

\section{Methods}

\section{Cell culture}

hMSCs were obtained from Cyagen Biosciences, Inc. (Guangzhou, China), and cultured in 90\% Dulbecco's modified Eagle medium (DMEM; Hyclone, Logan, UT, USA) supplemented with $10 \%$ fetal bovine serum (FBS; Invitrogen, Carlsbad, CA, USA), $100 \mathrm{IU} / \mathrm{ml}$ penicillin (Hyclone, Logan, UT, USA), and $100 \mu \mathrm{g} / \mathrm{ml}$ streptomycin (Hyclone, Logan, UT, USA). The medium was changed every 2 days. After reaching 90\% confluence, cells were detached by incubating with $0.125 \%$ trypsin for $1-2 \mathrm{~min}$ at $37{ }^{\circ} \mathrm{C}$ and replated for continuous passage. Cells between 5 and 10 passages were used for all experiments. The rat cardiomyocyte cell line $\mathrm{H} 9 \mathrm{c} 2$ was purchased from the Laboratory Animal Center of Sun Yat-sen University. The human cardiomyocyte cell line AC16 was kindly supplied by Drs. Yangxin Chen and Yong Xie, Sun Yat-sen Memorial Hospital [11]. Cells were maintained in DMEM supplied with 10\% FBS and 1\% antibiotic solution.

\section{Construction of ISL1-hMSCs}

The detail of construction and characterization of ISL1hMSCs are described in our prior publication [10]. In brief, entry vectors were generated by flanking the human EF1 $\alpha$ promoter and human ISL1 gene with attB4/B1r and attB1/B2 sites, respectively, by polymerase chain reaction (PCR). The promoter PCR product was cloned into pDONR P4-P1r (Invitrogen, Carlsbad, CA, USA) using the Gateway BP recombination method. The att-flanked ISL1 fragment was cloned into pDONR 221 (Invitrogen, Carlsbad, CA, USA) using the same method. The resulting vectors, termed pUp-EF1 $\alpha$ and pDown-ISL1, were recombined into the pDest-puro vector using a recognized LR recombination reaction protocol described in the Gateway LR kit and a clonase enzyme mix. The final lentiviral expression vector was designated $\mathrm{pLV} /$ puro-EF1 $\alpha$-ISL1 (EF1 $\alpha$-ISL1). The control vector, $\mathrm{pLV} /$ puro-EF1 $\alpha$-empty (EF1 $\alpha$-Empty) was transduced into hMSCs as a control.

Lentiviruses were prepared by transient cotransfection of 293FT cells with the EF1 $\alpha$-ISL1 construct or EF1 $\alpha$ Empty together with the ViraPower Lentiviral packaging mix (Invitrogen, Carlsbad, CA, USA) using Lipofectamine 2000 (Invitrogen, Carlsbad, CA, USA). Three days after transfection, supernatants containing viral particles were harvested, filtered through polyether sulfone membranes (pore size $0.45 \mu \mathrm{m}$ ), and titered.

For lentiviral transduction, hMSCs were dissociated into single-cell suspensions using 0.125\% TrypLE Select (Invitrogen, Carlsbad, CA, USA) and then replated with 
lentiviral particles and $5 \mu \mathrm{g} / \mathrm{ml}$ polybrene (Sigma-Aldrich, St. Louis, MO, USA). The medium was replaced with fresh culture medium 12-24 h after infection. Four days after transduction, puromycin (Sigma-Aldrich, St. Louis, MO, USA) was added to the culture medium at a concentration of $1-5 \mu \mathrm{g} / \mathrm{ml}$, and the cells were maintained in this medium for 5 days. Ultimately, ISL1-hMSCs (ISL1 overexpression hMSCs) and Ctrl-hMSCs (empty vector control hMSCs) were obtained.

\section{Characterization of ISL1-hMSCs}

ISL1-hMSCs or Ctrl-hMSCs were analyzed by flow cytometry with primary fluorescence using fluorescein isothiocyanate (FITC)-conjugated (anti-CD29, anti-CD34, and anti-CD45) or phycoerythrin (PE)-conjugated (anti-CD14, anti-CD31, anti-CD73, and anti-CD90) antibodies (BD Biosciences, San Diego, CA). Irrelevant isotype-matched antibodies (BD Biosciences, San Diego, CA) were used as negative controls. Flow cytometry analyses were performed with an Influ cell sorter (BD Biosciences, San Diego, CA). The data were analyzed using FlowJo7.5 software (Treestar, Ashland, OR, USA).

\section{Stem cell differentiation assay}

For osteogenic differentiation, the cells were incubated in osteogenic medium containing $10 \mu \mathrm{M}$ dexamethasone, 0.2 $\mathrm{mM}$ ascorbic acid, and $10 \mathrm{mM} \beta$-glycerophosphate (Sigma-Aldrich, St. Louis, MO, USA). The medium was replaced twice weekly. After 14 days in differentiation medium, the cells displayed bone-like nodular aggregates of matrix mineralization. Mineral deposition was visualized by Alizarin Red S staining for calcium.

For chondrogenic differentiation, cells were cultured in complete medium supplemented with $100 \mu \mathrm{g} / \mathrm{mL}$ sodium pyruvate, $10 \mathrm{ng} / \mathrm{mL}$ transforming growth factor (TGF)- $\beta 1$, $100 \mathrm{nM}$ dexamethasone, $1 \%$ insulin-transferrin-selenium, and $100 \mu \mathrm{g} / \mathrm{mL}$ ascorbate-2-phosphate. To evaluate the deposition of glycosaminoglycans, after 14 days the cells were fixed with $10 \%$ formalin for $20 \mathrm{~min}$ and stained with Alcian Blue 8GX (Cyagen Biosciences, Guangzhou, China) for $30 \mathrm{~min}$.

For adipogenesis [12], induction and maintenance media were used alternately for 3 days. The induction medium consisted of DMEM (high glucose), 10\% FBS, $1 \%$ antibiotic solution, $0.5 \mathrm{mM}$ 1-methyl-3-isobutylxanthine (IBMX), $200 \mathrm{mM}$ indomethacin, $10 \mathrm{mg} / \mathrm{ml}$ insulin, and $0.1 \mathrm{mM}$ dexamethasone (Sigma-Aldrich, St. Louis, MO, USA). The maintenance medium consisted of DMEM, 10\% FBS, 1\% antibiotic solution, and $10 \mathrm{mg} /$ $\mathrm{ml}$ insulin. Adipogenic differentiation was analyzed by Oil-Red O staining (Sigma-Aldrich, St. Louis, MO, USA) after induction for 2-3 weeks.

\section{Quantitative reverse-transcription PCR (qRT-PCR)}

Total RNA was extracted from cells using TRIzol Reagent (Invitrogen, Carlsbad, CA, USA). Samples $(1 \mu \mathrm{g})$ of total RNA were reverse-transcribed using a First Strand complementary DNA synthesis kit for RT-PCR (Roche, Indianapolis, IN, USA). qRT-PCR was performed using SYBR PCR Master Mix (Toyobo, Japan) according to the manufacturer's instructions. qRT-PCR was conducted in duplicate for each sample, and three independent experiments were performed. Signals were detected using a Light Cycler 480 detection system (Roche, Indianapolis, IN, USA). The primer sequences are listed in Additional file 1: Table S1.

\section{Myocardial infarction studies}

Three-month-old Sprague-Dawley rats were used to establish an MI model, as previously described [13]. The Sprague-Dawley rats were supplied by the Animal Center, Sun Yat-sen University. The animal study was approved by the Animal Care and Use Committee of Sun Yat-sen University. Rats (37 in total, five rats died during or after the surgery) were divided into four groups: the sham group $(n=8)$, the control group $(n=8)$, the Ctrl-hMSCs group $(n=8)$, and the ISL1-hMSCs group $(n=8)$. Briefly, the rats were anesthetized with ketamine $(100 \mathrm{mg} / \mathrm{kg}$ intraperitoneally) prior to undergoing a left intercostal thoracotomy. After the left anterior descending coronary artery (LAD) was identified it was ligated directly below the left atrial appendage with 8-0 nylon sutures. Abnormalities in the pallor and regional wall motion of the left ventricle confirmed the occlusion. In some groups, a total of $10^{6} \mathrm{CM}$-Dil-labeled cells (in $50 \mu \mathrm{L}$ DMEM) or $50 \mu \mathrm{L}$ DMEM alone was injected intramuscularly into two sites of the ischemic border zone. The chest wall was then closed, the lungs were inflated, the rat was extubated, and the tracheotomy was closed. After recovery, the rats were returned to the animal facility for 1-28 days. The ligated hearts were harvested at different time intervals after LAD ligation (7 and 28 days) and embedded in optimal cutting temperature (OCT) compound (Sakura Finetek, Torrance, USA). Frozen sections $(10 \mu \mathrm{m})$ were collected for each whole heart and prepared for immunofluorescence staining. For histological staining, the ligated hearts were fixed in $4 \%$ paraformaldehyde and embedded in paraffin. The sections were stained using Masson's trichrome stain.

\section{Echocardiography analysis}

Echocardiography was performed (GE vivid 7 dimension) to determine cardiac structure and function in conscious rats. Hearts were viewed in the short-axis between the two papillary muscles, and each measurement was obtained in M-mode by averaging the results from three consecutive heart beats. Fractional shortening (FS) and the left ventricular ejection fraction $(E F)$ were 
automatically calculated using the echocardiography software according to the Teicholz formula. Parameters were measured to determine structural changes in cardiac morphology. The individuals performing the echocardiography were blinded to the animal treatments.

\section{Immunofluorescence and immunohistochemistry}

Prior to immunofluorescence analyses, cells were fixed in $4 \%(\mathrm{v} / \mathrm{v})$ paraformaldehyde for $20 \mathrm{~min}$ and then permeabilized by incubation for $30 \mathrm{~min}$ at room temperature in phosphate-buffered saline (PBS) containing $0.1 \%(\mathrm{v} / \mathrm{v})$ Triton X-100, goat serum, and $1 \%(\mathrm{w} / \mathrm{v})$ bovine serum albumin (BSA; Sigma). Cells were incubated overnight at 4 ${ }^{\circ} \mathrm{C}$ with primary antibodies against ISL1 (1:300, cat. no. ab178400, Abcam, Cambridge, UK), $\alpha$-actinin (1:200, cat. no. ab50599, Abcam, Cambridge, UK) to detect cardiomyocytes, CD3 (1:300, cat. no. ab16669, Abcam, Cambridge, UK) to detect $\mathrm{T}$ lymphocytes, and CD68 (1:300, cat. no. ab125212, Abcam, Cambridge, UK) to detect macrophages. Inflammation factors interleukin (IL)-6 (1:400, cat. no. Ab9324, Abcam, Cambridge, UK), IL-10 (1:100, cat. no. Ab9969, Abcam, Cambridge, UK), and tumor necrosis factor (TNF)- $\alpha$ (1:100, cat. no. Ab6671, Abcam, Cambridge, UK) were also detected. Rabbit IgG secondary antibody, Alexa Fluor 594 (1:400, cat. no. A-21207, Invitrogen, Carlsbad, CA, USA) or mouse IgG secondary antibody, Alexa Fluor 594 (1:400, cat. no. A21203, Invitrogen, Carlsbad, CA, USA) were added, and the incubation was performed at room temperature for $1 \mathrm{~h}$ in the dark. Nuclei were counterstained with 4'6-diamidino-2-phenylindole (DAPI; 1:1000, cat. no. D9542, SigmaAldrich, St. Louis, MO, USA).

Formalin-fixed and paraffin-embedded samples were deparaffinized and rehydrated. After rinsing with PBS, antigen retrieval was carried out by microwave treatment in $0.01 \mathrm{M}$ sodium citrate buffer $(\mathrm{pH} 6.0)$ at $100{ }^{\circ} \mathrm{C}$ for 15 min. Antibody incubations were as follows: CD31 antibody (1:400, cat. no. Ab119339, Abcam, Cambridge, UK) was used to detect capillaries; human anti-nuclei antibody (HNA; 1:400, cat. no. MAB1281, Millipore, Bedford, MA, USA) was used to track grafted cells. For immunohistochemistry assessment, nuclei counterstaining was performed and brown-yellow staining was considered positive expression.

\section{Cell survival assay}

The influence of ISL1 transduction on hMSC survival was determined by seeding $1 \times 10^{5}$ ISL1-hMSCs or control cells per well in a six-well plate. After incubation overnight, media were replaced with serum-free DMEM, and the cells were cultured for an additional $48 \mathrm{~h}$. ISL1-

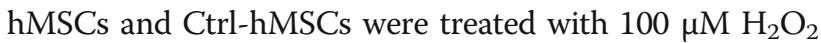
for $8 \mathrm{~h}$. Cell survival was determined by fluorescenceactivated cell sorting (FACS) using Annexin V/propidium iodide (PI) antibodies. The data were analyzed using FlowJo7.5 software (Treestar, Ashland, OR, USA).

\section{Conditioned medium (CM) preparation}

$\mathrm{CM}$ was prepared according to our previous reports [14]. After the Ctrl-hMSCs or ISL1-hMSCs had reached greater than $80 \%$ confluence, the cells were cultured with serum-free DMEM for another $24 \mathrm{~h}$. The medium from $10^{6}$ cells yielded $6 \mathrm{ml}$ of primary CM, which was further de-salted and concentrated 30 -fold by centrifugation $\left(4000 \times \mathrm{g}\right.$ for $30 \mathrm{~min}$ at $\left.4{ }^{\circ} \mathrm{C}\right)$ using ultrafiltration units with a 3-kDa molecular weight cutoff (Amicon Ultra-PL 3; Millipore, Billerica, MA, USA), yielding 200 $\mu \mathrm{l}$ of concentrated CM. Serum-free DMEM (de-salted and concentrated 30-fold) served as a vehicle control. $\mathrm{CM}$ was used immediately or stored at $-80{ }^{\circ} \mathrm{C}$.

\section{IGFBP3 inhibition assay}

For the neutralization of IGFBP3 in CM, different concentrations of anti-IGFBP3 antibody (IGFBP3-Ab, R\&D Systems, Minneapolis, MN, USA) were added: $0.25 \mu \mathrm{g} /$ $\mathrm{mL}, 0.5 \mu \mathrm{g} / \mathrm{mL}, 1 \mu \mathrm{g} / \mathrm{mL}, 1.5 \mu \mathrm{g} / \mathrm{mL}$, and $2 \mu \mathrm{g} / \mathrm{mL}$ IGFBP3-Ab was preincubated in medium for $30 \mathrm{~min}$. Then, CM was added. Cells with or without CtrlhMSCs-CM or ISL1-hMSCs-CM were subjected to 200 $\mu \mathrm{M} \mathrm{H}_{2} \mathrm{O}_{2}$ for $6 \mathrm{~h}$ to detect apoptosis.

\section{Transferase-mediated deoxyuridine triphosphate-biotin nick end labeling (TUNEL assay)}

To detect cardiomyocyte apoptosis, an in-situ apoptotic cell death detection kit (cat. no. 11684795910, Roche, Indianapolis, IN, USA) based on the TUNEL assay was used. For the in vivo experiment, paraffin sections of heart were stained with TUNEL reagent. Brown-yellow staining in the nuclei was considered positive expression for immunohistochemistry assessment. Green fluorescence was positive for the immunofluorescence assay.

For the in vitro experiment, the cardiomyocyte cell line $\mathrm{H} 9 \mathrm{c} 2$ with or without Ctrl-hMSCs-CM or ISL1hMSCs-CM was subjected to $200 \mu \mathrm{M} \mathrm{H}_{2} \mathrm{O}_{2}$ for 6 h. Cell nuclei were stained with DAPI (blue) and TUNEL positive (green). The percentage of apoptotic nuclei per section was calculated by counting the number of TUNEL staining cardiomyocyte nuclei divided by the total number of DAPI-positive nuclei.

\section{Western blotting}

Cell lysates with equal total protein amounts were separated by SDS-PAGE gel. Proteins were transferred electrophoretically to polyvinylidene difluoride (PVDF) membranes (Bio-Rad). The membranes were blocked in $5 \%$ milk in PBS-T $(0.1 \%$ Tween 20$)$ at room temperature for $1 \mathrm{~h}$. The membranes were probed with primary antibody specific for caspase 3 , cleaved caspase 3, caspase 
9, cleaved caspase 9, Bax, Bcl2 (1:1000, Cell Signaling Technology), or $\beta$-actin (1:10,000, Cell Signaling Technology). The primary antibody was then identified by a horseradish peroxidase (HRP)-conjugated secondary antibody diluted 1:5000 (Cell Signaling Technology). Finally, the membranes were developed using an enhanced chemiluminescence (ECL) advance detection kit (GE healthcare) and exposed to $\mathrm{x}$-ray films. The band density was analyzed using ImageJ software (Rawak Software, Inc., Germany).

\section{RNA sequencing}

Ctrl-hMSCs or ISL1-hMSCs were prepared. RNA library preparation and sequencing were performed as recommended by the manufacturer (Genome Analyzer IIx, Illumina, USA). Sequencing data were processed using Consensus Assessment of Sequence and Variation software (Illumina) with default settings. Genes with RPKM (reads per kilobase of exon per million mapped reads) values of more than five were enrolled in the functional analysis according to the Gene Ontology (GO) database. Genes related to apoptosis were selected to draw a heatmap with HemI (Heatmap Illustrator, Huazhong University of Science and Technology, China).

\section{Enzyme-linked immunosorbent assay (ELISA)}

The levels of IGFBP3 in the conditioned medium of Ctrl-hMSCs or ISL1-hMSCs were determined by ELISA using commercially available Quantikine kits (R\&D Systems, Minneapolis, MN, USA) according to the manufacturer's instructions. All samples and standards were measured in duplicate.

\section{Proliferation assay}

Isolated $\mathrm{CD}^{+} \mathrm{T}$ lymphocytes were stained using a CellTrace CFSE cell proliferation kit $(5 \mathrm{mmol} / \mathrm{L}$; Invitrogen, Carlsbad, CA, USA) according to the manufacturer's instructions. Labeled $\mathrm{CD}^{+} \mathrm{T}$ cells were cultured in replicate wells with or without hMSCs and stimulated with an antiCD3 monoclonal antibody $(0.2 \mathrm{mg} / \mathrm{mL}$, BD Biosciences, San Diego, CA) and an anti-CD28 monoclonal antibody (1 mg/mL, BD Biosciences, San Diego, CA) for $96 \mathrm{~h}$. T-cell proliferation was evaluated by flow cytometric analysis of 5,6-carboxyfluorescein diacetate succinimidyl ester (CFSE) dilutions.

\section{Intracellular cytokine staining}

$\mathrm{CD}^{+} \mathrm{T}$ cells were sorted from healthy donors, resuspended in RPMI 1640 medium (Hyclone, Logan, UT, USA), and cultured in duplicate wells with or without CtrlhMSCs or ISL-hMSCs for $72 \mathrm{~h}$. Brefeldin A (BFA; $10 \mathrm{mg}$ / $\mathrm{mL}$, Sigma-Aldrich, St. Louis, MO, USA), phorbol-12myristate-13-acetate (PMA; $50 \mathrm{ng} / \mathrm{mL}$, Sigma-Aldrich, St. Louis, MO, USA), and ionomycin $(1 \mathrm{mg} / \mathrm{mL}$, SigmaAldrich, St. Louis, MO, USA) were added, and the cells were cultured for an additional $6 \mathrm{~h}$. The cells were fixed, permeabilized, and cell-surface stained using v450conjugated CD3 (CD3-v450), PE-conjugated TNF $\alpha$-PE, and PE-cyanine 7-conjugated interferon- $\gamma$ (IFN- $\gamma$-PE-Cy7). All three antibodies were purchased from BD Biosciences (San Diego, CA, USA).

\section{Statistical analysis}

All results represent data collected from at least three independent experiments. Statistical analyses were performed using one-way analyses of variance (ANOVA). Post-hoc tests were used for statistical tests. A $p$ value $<0.05$ was considered a statistically significant difference. All data are expressed as the means \pm standard deviation (SD).

\section{Results}

\section{Expression of ISL1 in hMSCs}

The lentiviral vector EF1 $\alpha$-ISL1 was constructed and viruses were produced as described in the Methods. The ISL1-hMSCs were generated by transducing wild-type hMSCs with ISL1 by exposure to EF1 $\alpha$-ISL1 lentivirus for $24 \mathrm{~h}$. After antibiotic selection, purified ISL1-hMSCs were obtained. The ISL1-hMSCs were characterized by multipotent differentiation potential and surface markers. Flow cytometry demonstrated that these cells were positive for the stem cell markers CD29, CD44, $\mathrm{CD} 73$, and $\mathrm{CD} 90$, but negative for the hematopoietic stem cell markers CD14, CD31, CD34, and CD45, indicating that transduced cells maintained the hMSC phenotype (Fig. 1a). Analysis by qRT-PCR showed that ISL1 overexpression was successfully achieved in hMSCs and that they had long-term stability in in-vitro cultures (Fig. 1b). Flow cytometry (Fig. 1c) and immunofluorescence staining (Fig. 1d) further confirmed the successful overexpression of ISL1 in hMSCs. The ISL1-hMSCs maintained the potential to differentiate into adipocytes, osteoblasts, and chondrocytes, demonstrating their multilineage differentiation potential. After specific induction, ISL1-hMSCs or Ctrl-hMSCs were positive for Alizarin Red, Oil-Red O and Alcian Blue staining (Fig. 1e).

\section{ISL1-hMSC transplantation improved cardiac function and attenuated myocardial infarct size}

To determine whether ISL1 enhances the therapeutic effect of stem cells, we evaluated the effects of hMSC transplantation on cardiac function and infarct size in post-MI rat hearts. Left ventricle EF and FS were greater in post-MI hearts at 4 weeks treated with ISL1-hMSCs than in CtrlhMSCs or PBS (Fig. 2). EF in the ISL1-hMSC group increased to $55.19 \pm 3.87 \%(p<0.05$ vs. MI at $28.03 \pm 4.10 \%$; $p<0.05$ vs. Ctrl-hMSCs at $42.43 \pm 3.03 \%)$. FS in the ISL1hMSC group increased to $30.20 \pm 4.41 \%$ ( $p<0.05$ vs. MI at $13.49 \pm 3.10 \% ; p<0.05$ vs. Ctrl-hMSCs at $22.01 \pm 3.04 \%$ ). Left ventricular end-diastolic volume (LVEDV) and left 


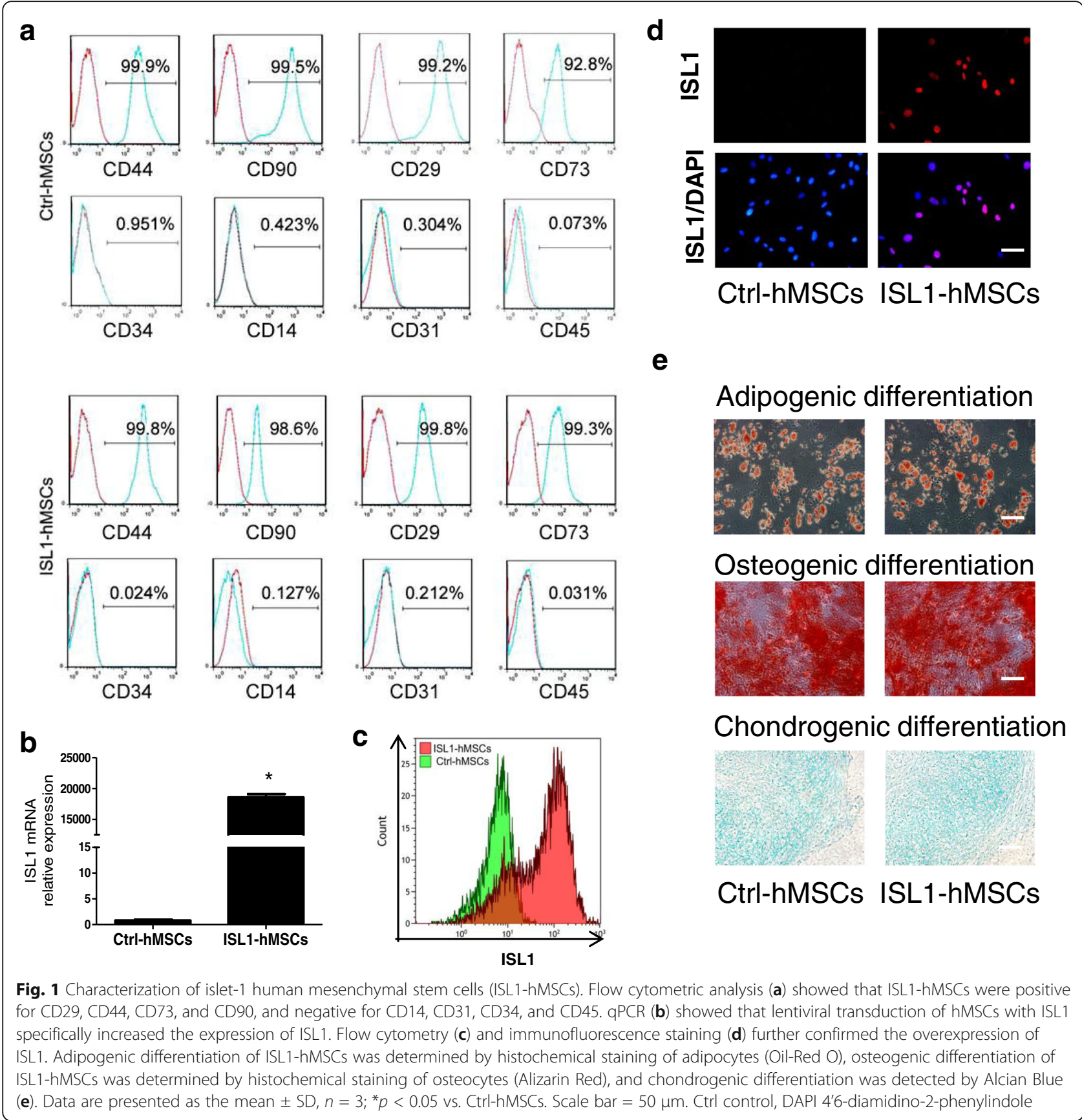

ventricular end-systolic volume (LVESV) were greater in post-MI hearts after 4 weeks of treatment with ISL1-hMSCs than PBS (Additional file 2: Figure S1a, b). Cardiac output (CO) in the sham group was $78.49 \pm 6.07 \mathrm{ml} / \mathrm{min}$, and it decreased to $46.41 \pm 6.19 \mathrm{ml} / \mathrm{min}$ in the MI group. In the Ctrl-hMSC group, CO increased to $59.36 \pm 6.54 \mathrm{ml} / \mathrm{min}(p$ $<0.05$ vs MI). In the ISL1-hMSC group, it recovered to $71.23 \pm 6.66 \mathrm{ml} / \mathrm{min}(p<0.05$ vs MI) (Additional file 2: Figure S1c). The myocardial infarct size was significantly smaller in rat hearts treated with ISL1-hMSCs than in those with Ctrl-hMSCs or PBS at 4 weeks post-MI (Fig. 3a).
Masson's trichrome staining showed an increase in the islands of viable cardiac muscle in the peri-infarct regions at 4 weeks after Ctrl-hMSC or ISL1-hMSC treatment (Fig. 3b). The percentage of the fibrotic area in the total peri-infarct zone was significantly reduced in hMSC-treated hearts, and ISL1-hMSCs further reduced the fibrotic area (Fig. 3c).

ISL1 overexpression increased angiogenesis and decreased apoptosis and inflammation

We also investigated the effects of ISL1-hMSCs on angiogenesis and inflammation in post-MI hearts. At 4 


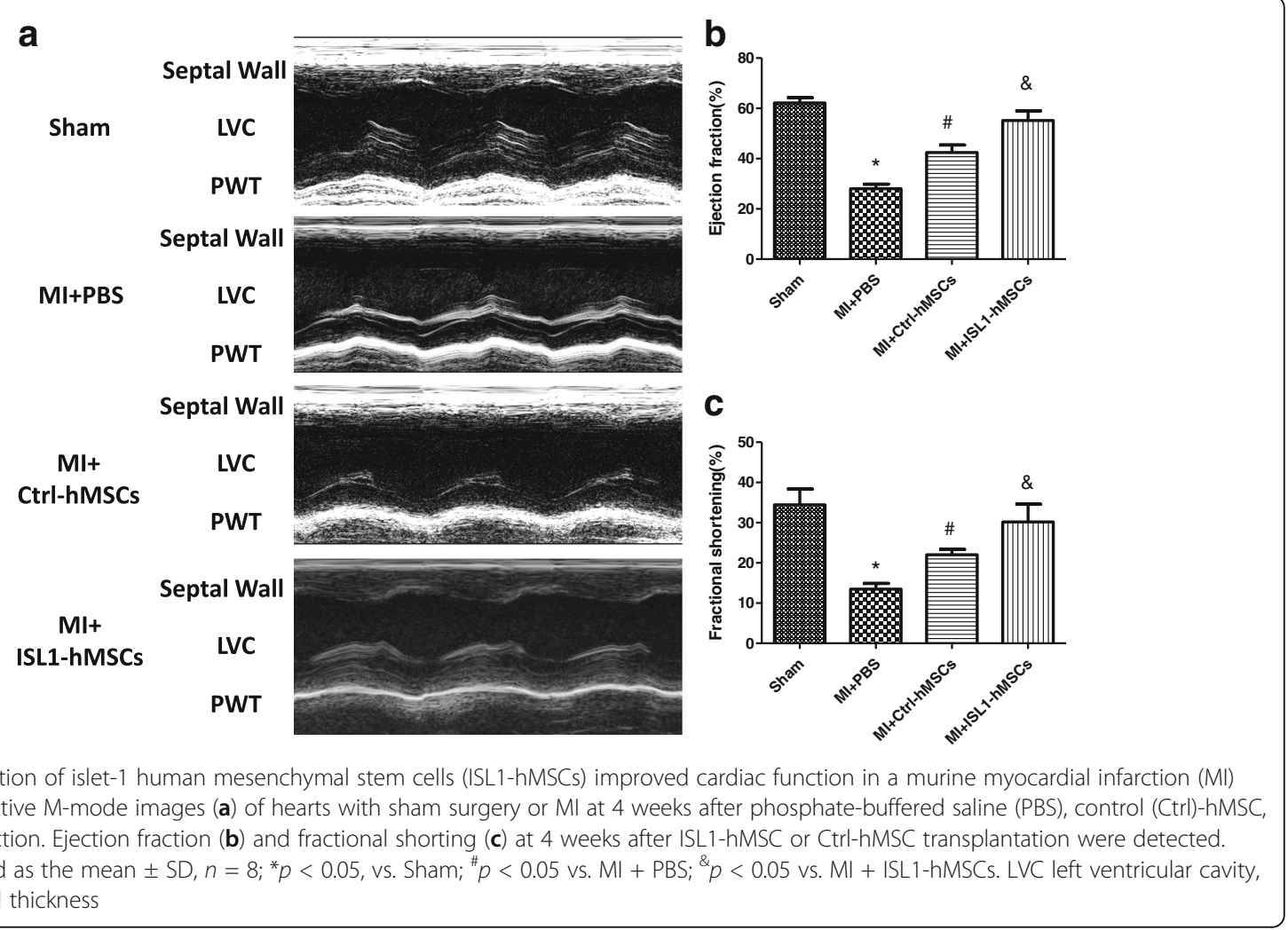

weeks after transplantation, immunostaining showed more CD31-expressing capillaries present in peri-infarct regions of ISL1-hMSC- versus Ctrl-hMSC-treated hearts (Fig. 4a, b), which suggested that ISL1-hMSC transplantation promoted angiogenesis.

The TUNEL assay was used to measure apoptotic cell death in the infarct border zone. The TUNEL-positive nucleus number was moderately reduced in Ctrl-hMSCtreated hearts and more significantly reduced in ISL1hMSC-treated hearts (Fig. 4c, d). We also used TUNEL/ $\alpha$ actinin double staining to detect positive apoptotic cardiomyocytes and found that ISL1-hMSC transplantation reduced TUNEL-positive cardiomyocytes compared to Ctrl-hMSCs or PBS (Additional file 2: Figure S2).

Inflammatory cell infiltration was analyzed by immunofluorescence after MI. ISL1-hMSCs reduced the amount of CD3-positive T cells (Additional file 2: Figure S3) and CD68-positive macrophages (Additional file 2: Figure S4). We also detected the inflammatory cytokines IL-6, IL-10, and TNF $\alpha$ in heart slides. ISL1-hMSC transplantation reduced the expression of inflammatory cytokines compared with the Ctrl-hMSC or PBS groups (Additional file 2: Figure S5). Furthermore, we analyzed the immunoregulatory effects of ISL1-hMSCs on the proliferation and proinflammatory cytokine production of $\mathrm{CD}^{+} \mathrm{T}$ cells in vitro. The results indicated that ISL1-overexpressing hMSCs markedly inhibited the proliferation of $\mathrm{CD}^{+} \mathrm{T}$ cells and decreased the percentages of TNF $\alpha$-producing and IFN- $\gamma$ producing $\mathrm{CD}^{+} \mathrm{T}$ cells, respectively, compared with the Ctrl-hMSC or PBS groups (Additional file 2: Figure S6), indicating that the enhanced therapeutic effect of ISL1-hMSCs might be partially associated with a reduced inflammatory response.

\section{ISL1 overexpression increased transplanted cell survival}

To quantify the survival of transplanted cells they were stained with CM-Dil before injection. There were significantly more surviving cells in the myocardium in the ISL1-hMSC group compared with the hMSC group 7 days after transplantation $(24.8 \pm 5.26 \%$ vs. $69.4 \pm 7.76 \%$, $n=3 ; p<0.05$ ). Human nuclear antigen (HNA) staining was also used to track grafted cells (Fig. 5a, b). The results were consistent with the CM-Dil tracking.

The improved survival rate of ISL1-hMSCs was confirmed by FACS analysis of cells treated with $\mathrm{H}_{2} \mathrm{O}_{2}$. Hypoxia and oxidative stress in the ischemic area of the post-MI heart are thought to be the main causes of the death of resident transplanted hMSCs and cardiomyocytes. $\mathrm{H}_{2} \mathrm{O}_{2}$ was used to treat hMSCs to simulate oxidative stress in vitro. The apoptosis of hMSCs was assessed by FACS analysis of Annexin V. The increase in Annexin V-positive cells induced by $\mathrm{H}_{2} \mathrm{O}_{2}$ was significantly blunted by ISL1 overexpression (Fig. 5c, d). Western blotting showed that the increases in cleaved caspase3/total caspase3 in hMSCs 


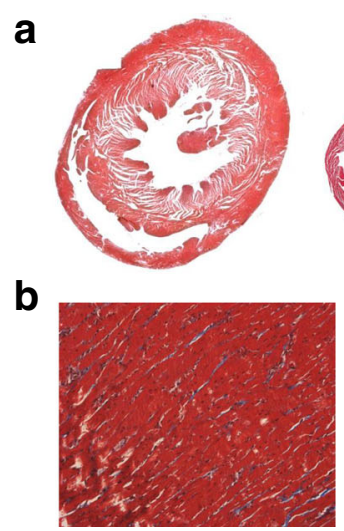

Sham
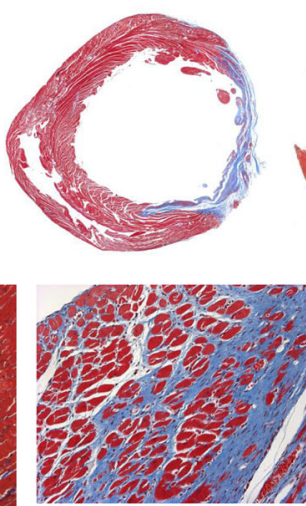

$\mathrm{MI}+\mathrm{PBS}$
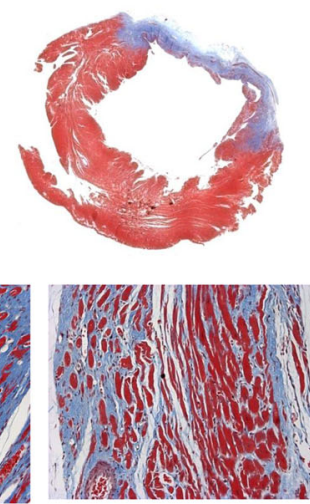

Ml+Ctrl-hMSCs
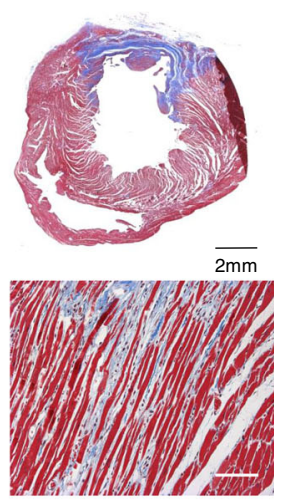

MI+ISL1-hMSCS

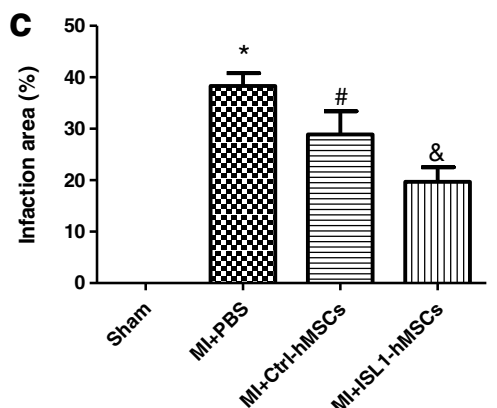

Fig. 3 Transplantation of islet-1 human mesenchymal stem cells (ISL1-hMSCs) reduced cardiac infarct size and fibrotic size in a myocardial infarction (MI) model. (a) Representative images of infarct size. Representative images (b) and quantification (c) of the fibrotic area in the infarct border zone by Masson's trichrome staining at 4 weeks post-Ml. Data are presented as the mean $\pm \mathrm{SD}, \mathrm{n}=8 ;{ }^{*} p<0.05$, vs. sham; ${ }^{*} p<0.05 \mathrm{vs}$. Ml + phosphate-buffered saline $(\mathrm{PBS}){ }^{{ }^{\&}} p<0.05$ vs. MI + ISL1-hMSCs. Scale bar $=50 \mu \mathrm{m}$. Ctrl control

were partly reversed by ISL1 overexpression (Fig. 5e). Bax, Bcl-2, cleaved caspase 9, and total caspase 9 were also detected by Western blotting. The results were consistent with those for caspase 3 (Additional file 2: Figure S7).

\section{ISL1 overexpression enhanced the secretion of anti-} apoptotic hMSC factors to protect cardiomyocytes We examined whether conditioned medium from ISL1overexpressing hMSCs affected the survival of the cardiomyocyte cell line H9c2. H9c2 cells were treated with 200 $\mu \mathrm{M} \mathrm{H}_{2} \mathrm{O}_{2}$ for $6 \mathrm{~h}$. TUNEL-positive cells were detected to determine the apoptotic index. hMSCs-CM decreased TUNEL-positive cells compared with H9c2 cells alone, and ISL1-hMSCs-CM further decreased TUNEL-positive cardiomyocytes. The apoptotic rate was $11.47 \pm 0.90 \%$ in the normal environment and $64.91 \pm 6.07 \%$ in oxidative environment. When Ctrl-hMSCs-CM was added, the apoptotic rate decreased to $49.24 \pm 7.58 \%$, while in the ISL1-hMSCs-CM group it was $25.80 \pm 5.67 \%$ (Fig. 6a, b).

\section{Gene expression profiling of Ctrl-hMSCs and ISL1-hMSCs}

To clarify the molecular basis of the anti-apoptotic effect, gene expression related to variable biological activities between Ctrl-hMSCs and ISL1-hMSCs was detected by
RNA-seq (accession number: PRJNA421054). A global overview of the RNA sequencing data is shown in Additional file 1: Tables S2 and S3. The top 10 GO functions of upregulated and downregulated genes of ISL1-MSCs are shown in Additional file 2: Figure S8. Secreted proteins with a RPKM value exceeding 100 in ISL1-hMSCs and Ctrl-hMSCs are shown in Additional file 2: Figure S9. Apoptosis-related secreted factors induced by Ctrl-hMSCs and ISL1-hMSCs are shown in Additional file 1: Table S4. Analysis of apoptosis-related genes showed a higher fold-change in GDF6, IGFBP3, TGFB1, GAS6, and INHBA, among other genes, in ISL1-hMSCs compared with Ctrl-hMSCs (Fig. 7a). To confirm our RNA-Seq results, the expression of the top five apoptosis-related genes with the highest fold-changes (including GDF6, IGFBP3, TGFB1, GAS6, and INHBA) were detected by qPCR in the other three pairs of hMSCs. The results showed that the expression of all five ISL1-hMSC genes was significantly higher than in Ctrl-hMSCs, in which the difference in IGFBP3 was the most prominent (Fig. $7 \mathrm{~b}$ ). We then selected genes by the RPKM value and difference ratio between Ctrl-hMSCs and ISL1-hMSCs. We found that IGFBP3 was the only gene with a RPKM value greater than 100 in ISL1-hMSCs, 


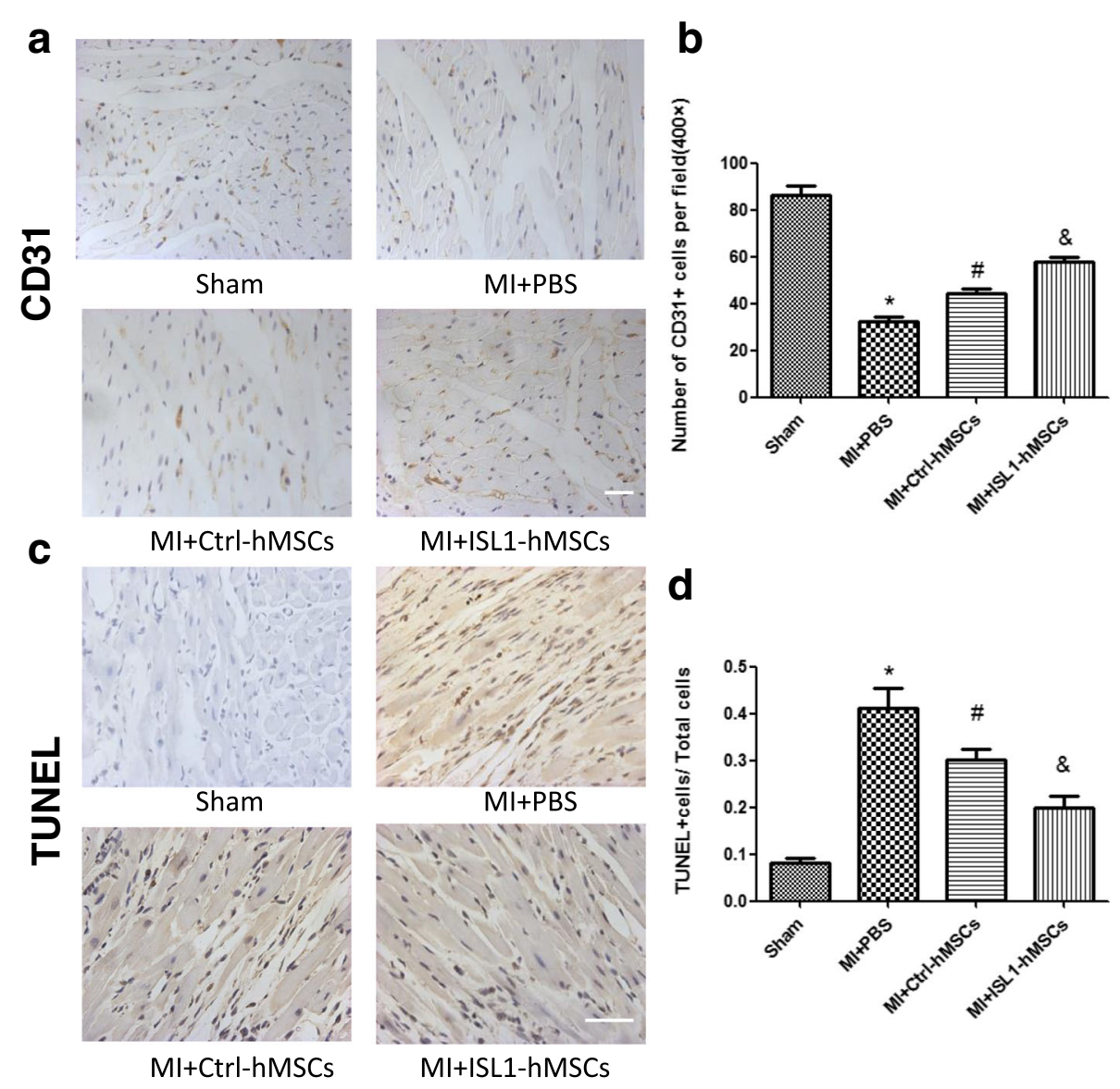

Fig. 4 Transplantation of islet-1 human mesenchymal stem cells (ISL1-hMSCs) increased angiogenesis and reduced apoptosis. Representative images (a) and quantification (b) of capillary density in the infarct border zone at 4 weeks post-myocardial infarct (MI) detected by CD31 staining. Representative images (c) and quantification (d) of TUNEL-positive cells in the infarct border. Data are presented as the mean $\pm \mathrm{SD}, \mathrm{n}=8$; ${ }^{*} p<0.05$, vs. sham; ${ }^{\sharp} p<0.05$ vs. MI + phosphate-buffered saline (PBS); ${ }^{p} p<0.05$ vs. MI + ISL1-hMSCs. Scale bar $=50 \mu \mathrm{m}$. Ctrl control

and the difference ratio was greater than 3 , which suggested that IGFBP3 paracrine proteins might play an important role in the anti-apoptosis effect of ISL1-hMSCs. To test this hypothesis, we detected the expression of IGFBP3 in the conditioned medium of ISL1-hMSCs and found that it was approximately three times greater than that of Ctrl-hMSCs $(787.89 \pm 68.13$ vs.198.64 $\pm 20.30 \mathrm{ng} /$ ml; Fig. 7c).

IGFBP3 in ISL1-hMSCs-CM had an anti-apoptotic effect on cardiomyocytes subjected to oxidative injury

Treatment of H9c2 cells with $200 \mu \mathrm{M} \mathrm{H}_{2} \mathrm{O}_{2}$ for $6 \mathrm{~h}$ caused apoptosis. hMSCs-CM decreased the number of TUNEL-positive cells, and ISL1-hMSCs-CM further decreased the number of TUNEL-positive cardiomyocytes. IGFBP3 neutralization antibody (IGFBP3-Ab) was used to inhibit the effect of IGFBP3 in CM. IGFBP3-Ab at different concentrations, $0.25,0.5,1,1.5$, or $2 \mu \mathrm{g} / \mathrm{mL}$, was added to the ISL1-hMSCs-CM. IGFBP3-Ab was pre-incubated in CM for $30 \mathrm{~min}$. ISL1-hMSCs-CM was then added. Cells with or without ISL1-hMSCs-CM were subjected to $200 \mu \mathrm{M} \mathrm{H}_{2} \mathrm{O}_{2}$ for another $6 \mathrm{~h}$. The TUNEL assay was performed to detect the reduction in active IGFBP3 in CM, and $1.5 \mu \mathrm{g} / \mathrm{mL}$ IGFBP3-Ab was the ideal concentration (Additional file 2: Figure S10). When 1.5 $\mu \mathrm{g} / \mathrm{mL}$ IGFBP3 neutralization antibody was used, the apoptotic effect of the ISL1-hMSCs-CM was clearly reversed, which confirmed the paracrine effect of IGFBP3 in the conditioned medium of ISL1-hMSCs on the rat cardiomyocyte cell line H9c2 (Fig. 8a, b). Similar effects were observed in the human cardiomyocyte cell line AC16 (Additional file 2: Figure S11). Overall, transplantation of hMSCs modified with ISL1 resulted in significantly greater cardiac functional improvement than transplantation of Ctrl-hMSCs in an MI model. Overexpression of ISL1 increased the survival of the transplanted hMSCs in an ischemic environment. Moreover, ISL1-hMSCs reduced the apoptosis of cardiomyocytes. A schematic of the effects of ISL1 on hMSCs and cardiomyocytes is shown (Fig. 8c). Secretion of IGFBP3 


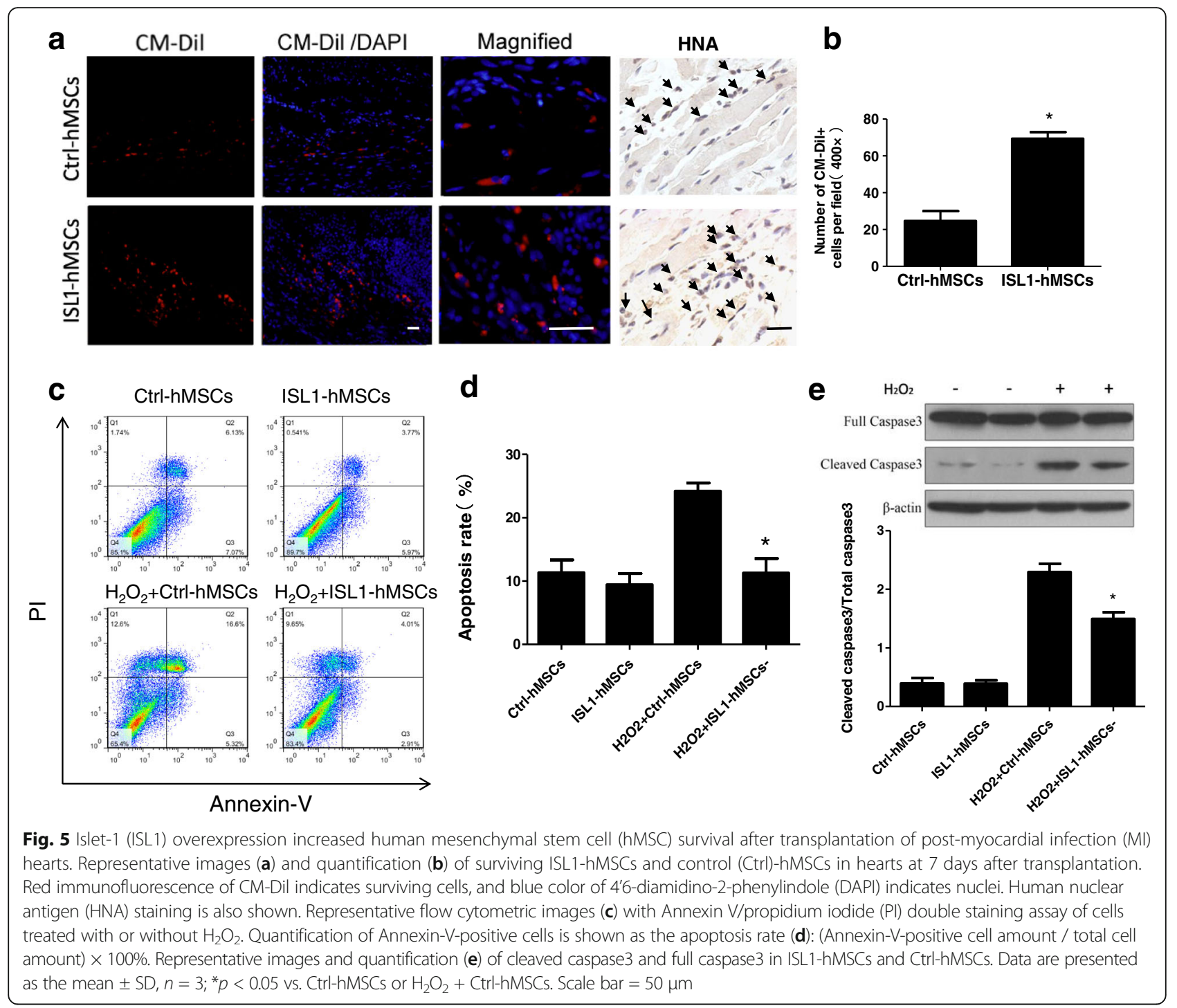

increased the survival of hMSCs and cardiomyocytes and improved heart ischemia.

\section{Discussion}

Stem cell therapy to repair damaged myocardium has evolved into a promising treatment for ischemic heart disease. One of the limitations of stem cell therapy for heart disease is the low survival rate of transplanted stem cells [15]. Apoptosis has been implicated as the main contributor to the massive loss of donor cells [16]. The major factor contributing to transplanted cell death appears to be the limited blood supply in the infarct zone that produces hypoxia and oxidative stress. The present study explored a novel approach to enhance the viability of stem cells injected into this harsh environment. We tested a novel hypothesis that overexpression of ISL1 in hMSCs would enhance their survival and protect their paracrine function when injected into the hostile environment of a post-MI heart. Transplantation of modified ISL1-hMSCs reduced the infarct size and improved cardiac function in a murine MI model. The greater potential of ISL1-hMSCs to reduce myocardial damage may be attributable to increased survival after transplantation. We observed that ISL1-hMSCs reduced $\mathrm{H}_{2} \mathrm{O}_{2}$-induced apoptosis in vitro. ISL1-hMSCs-CM also decreased the apoptotic effect of $\mathrm{H}_{2} \mathrm{O}_{2}$ in the cardiomyocyte cell line $\mathrm{H} 9 \mathrm{c} 2$. Our study provides strong support for approaches that enhance the survival and function of stem cells injected into hearts with a limited blood supply.

ISL1 has been shown to play an essential role in heart embryogenesis, and ISL1-positive cells have been demonstrated to be cardiovascular progenitors $[17,18]$. Although a recent study demonstrated that overexpression of ISL1 in MSCs induced cardiomyocyte differentiation [19], a prior study conducted by our group obtained different results 

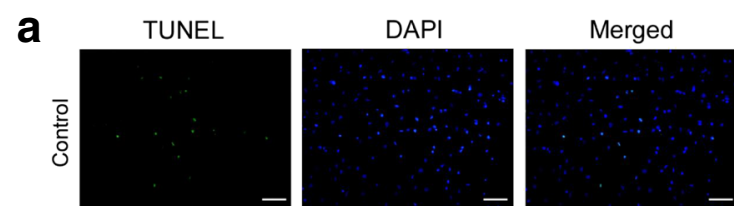

b
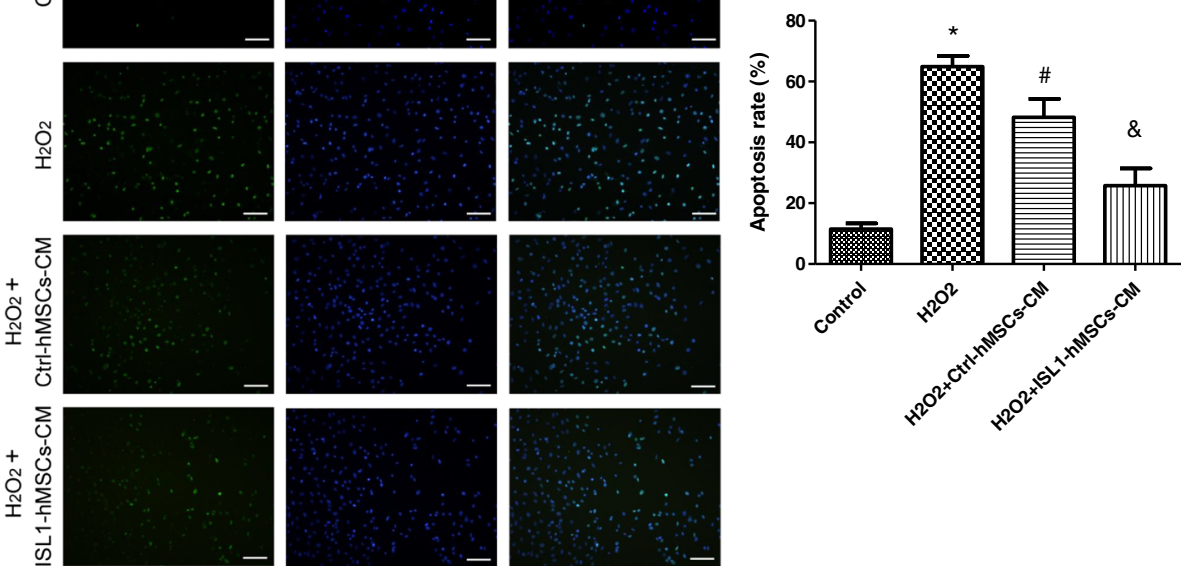

Fig. 6 The anti-apoptotic effect of islet-1 human mesenchymal stem cells (ISL1-hMSCs) conditioned medium (CM) on cardiomyocyte cell line $\mathrm{H} 9 \mathrm{C} 2$ subjected to oxidative injury (a) and quantification (b) of TUNEL staining in cardiomyocytes subjected to $200 \mu \mathrm{M} \mathrm{H} \mathrm{H}_{2} \mathrm{O}_{2}$ for 6 h. Cell nuclei were stained with 4'6-diamidino-2-phenylindole (DAPl; blue) and TUNEL-positive nuclei (green). Apoptosis rate = (TUNEL-positive nuclei / DAPI-positive nuclei) $\times 100 \%$. Data are presented as the mean $\pm \mathrm{SD}, \mathrm{n}=3 ;{ }^{*} p<0.05$ vs. control; ${ }^{\#} p<0.05$ vs. $\mathrm{H}_{2} \mathrm{O}_{2} ;{ }^{*} p<0.05$ vs. $\mathrm{H}_{2} \mathrm{O}_{2}+\mathrm{Ctrl}-\mathrm{hMSCs}$. Scale bar $=100$ $\mu \mathrm{m}$. Ctrl control
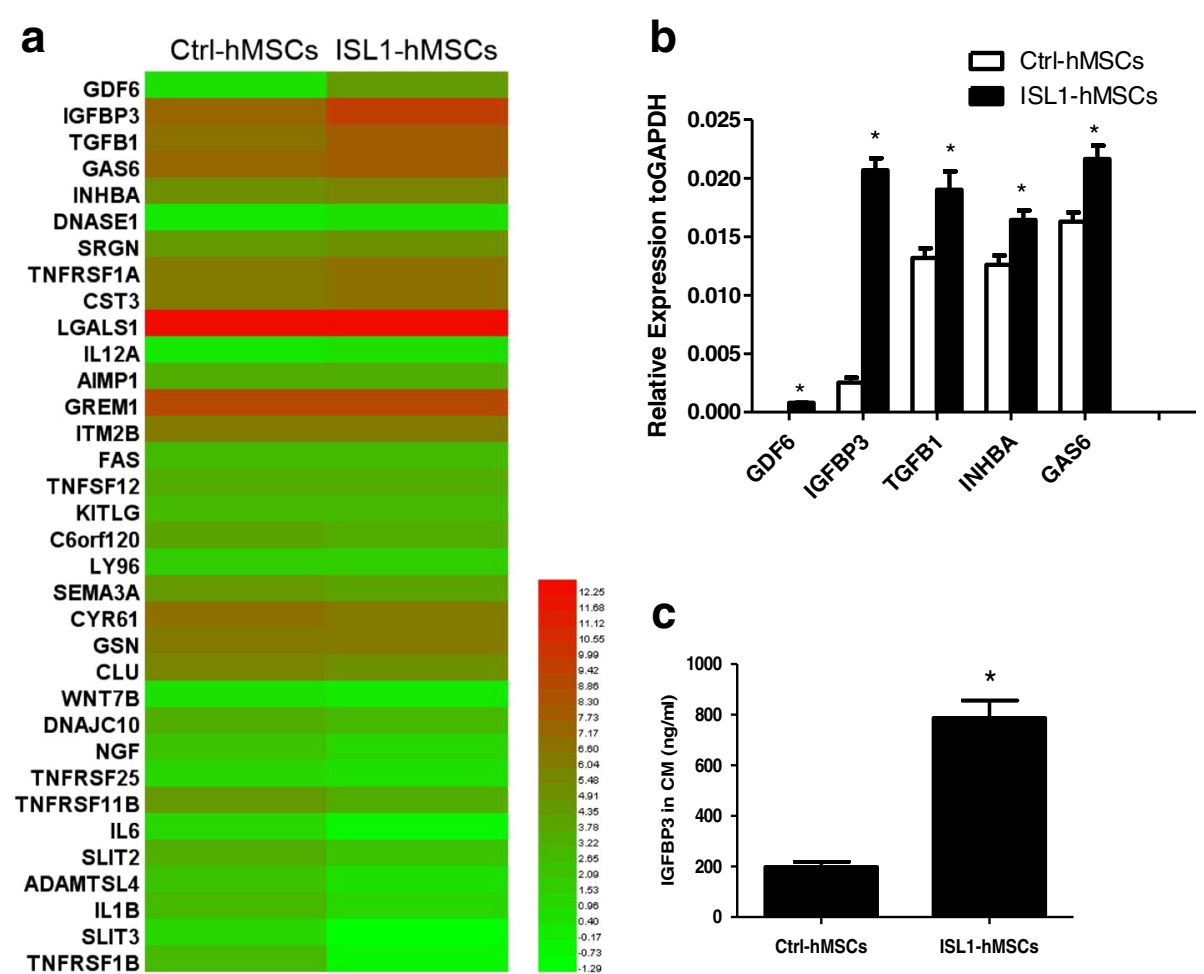

Fig. 7 Islet-1 (ISL1) overexpression enhanced the human mesenchymal stem cell (hMSC) paracrine effect by increasing insulin-like growth factor binding protein 3 (IGFBP3) secretion. A heat map display of apoptosis-related genes between ISL1-hMSCs and control (Ctrl)-hMSCs (a). GDF6, IGFBP3, TGFB1, GAS6, and INHBA gene expression in Ctrl-hMSCs and ISL1-hMSCs were determined by qPCR (b). IGFBP3 in Ctrl-hMSC conditioned medium (CM) and ISL1-hMSCs-CM determined by ELISA assay (c). Data are presented as the mean \pm SD, $n=3 ;{ }^{*} p<0.05$ vs. Ctrl-hMSCs. GAPDH glyceraldehyde-3-phosphate dehydrogenase 

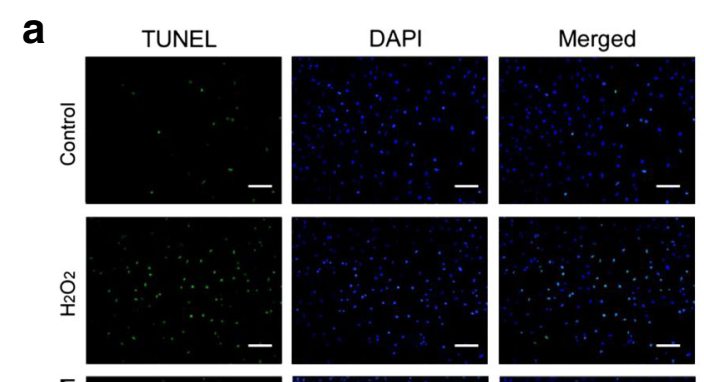

b
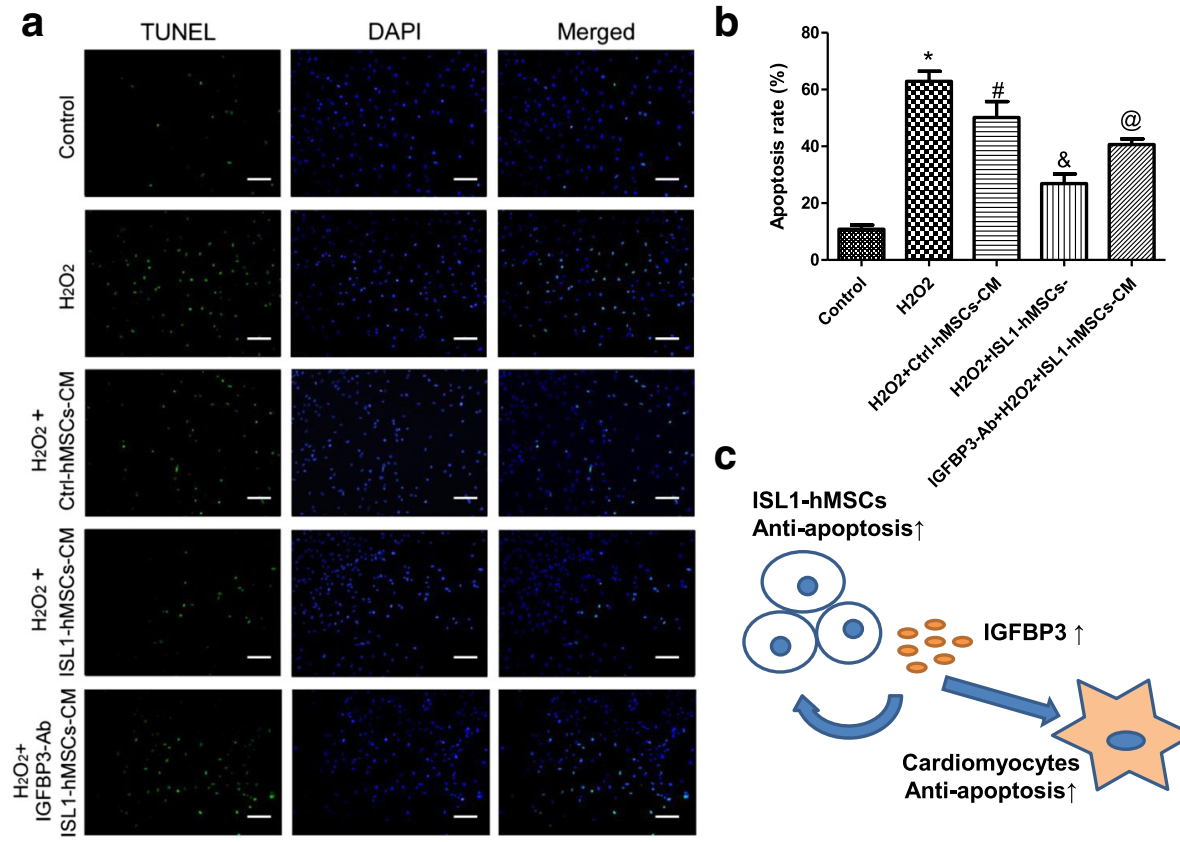

ISL1-hMSCs

Anti-apoptosis $\uparrow$
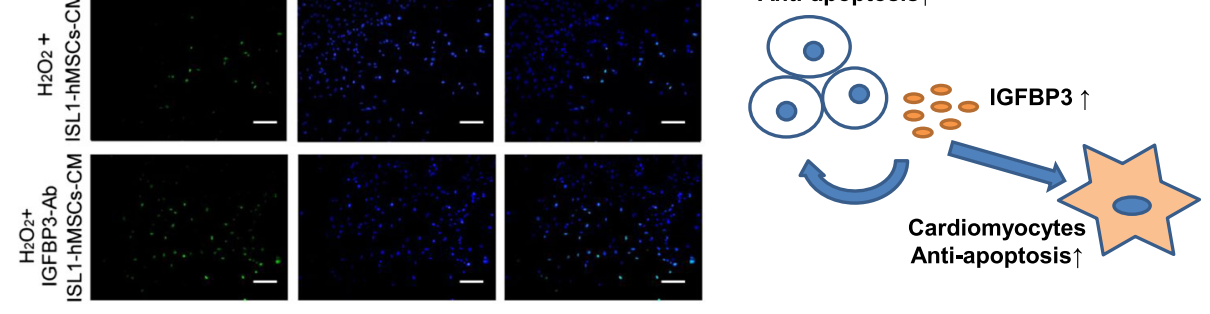

Fig. 8 The anti-apoptotic effect of insulin-like growth factor binding protein 3 (IGFBP3) in islet-1 human mesenchymal stem cells (ISL1-hMSCS) conditioned medium (CM) on cardiomyocytes subjected to oxidative injury. Representative images of TUNEL staining in cardiomyocytes (a). Cell nuclei were stained with 4'6-diamidino-2-phenylindole (DAPl; blue) and TUNEL-positive nuclei (green). Quantification of TUNEL staining was shown. Apoptosis rate $=($ TUNEL positive nuclei / DAPI + nuclei) $\times 100 \%$ (b). Graphic of the mechanisms underlying the therapeutic effects of transplantation of ISL1-hMSCs (c). Data are presented as the mean $\pm \mathrm{SD}, n=3 ;{ }^{*} p<0.05$ vs. control; ${ }^{\#} p<0.05$ vs. $\mathrm{H}_{2} \mathrm{O}_{2}{ }^{\circ}{ }^{\&} p<0.05$ vs. $\mathrm{H}_{2} \mathrm{O}_{2}+\mathrm{Ctrl}-\mathrm{hMSC} ;{ }^{\circledR} p<0.05$ vs. $\mathrm{H}_{2} \mathrm{O}_{2}+$ ISL1-hMSCs. Scale bar $=100 \mu \mathrm{m}$. Ctrl control

[10]. In our previous study, we found that ISL1 overexpression did not affect their ability to differentiate into cardiomyocytes or endotheliocytes. Further studies suggest that overexpression of ISL1 in hMSCs promotes angiogenesis in vitro and in vivo by increasing the secretion of paracrine factors. In the present study, ISL1-hMSCs reduced $\mathrm{H}_{2} \mathrm{O}_{2}$-induced apoptosis in vitro. In addition, ISL1-hMSCs-CM decreased the apoptotic effect of $\mathrm{H}_{2} \mathrm{O}_{2}$ in the cardiomyocyte cell line $\mathrm{H} 9 \mathrm{c} 2$. All the aforementioned results suggested that the effects of ISL1-hMSCs were mainly due to a paracrine effect and not cardiomyocyte differentiation [10].

Previous research has suggested that the ISL1 gene is an attractive reparative target for the treatment of myocardial dysfunction. Barzelay et al. [20] reported that ISL1 gives rise to subpopulations of progenitors in bone marrow and spleen and is re-expressed in the spleen and left ventricle following MI. Intramyocardial gene transfer of ISL1 to the border zone of infarcted hearts results in partial salvage of left ventricular function, enhanced vascularization, and reduced myocardial fibrosis [20]. Li et al. reported that $\mathrm{ISL}^{+}$cardiac progenitor cells (CPCs), when combined with a suitable vehicle, can produce notable therapeutic effects in the infarcted heart [21]. However, whether the role of ISL1 in recovery after MI is related to an anti-apoptosis effect remains unknown. In our study, ISL1-hMSCs reduced $\mathrm{H}_{2} \mathrm{O}_{2}$-induced apoptosis in vitro. ISL1-hMSCs-CM decreased the apoptotic effect of $\mathrm{H}_{2} \mathrm{O}_{2}$ on the cardiomyocyte cell line H9c2. Due to ischemia, hypoxia, and oxidative stress following infarction, the ability of transplanted cells to survive is compromised, which severely reduces the therapeutic effect of stem cell transplantation [22, 23]. This is one of the major barriers to cell therapy in the treatment of MI [24]. Therefore, promoting survival through modulation of the cellular microenvironment is a promising approach for successful stem cell therapy [25]. Our results showed an increased number of surviving cells after transplantation. ISL1-hMSCs also reduced $\mathrm{H}_{2} \mathrm{O}_{2}$-induced apoptosis in vitro. ISL1-hMSCs-CM decreased the apoptotic effect of $\mathrm{H}_{2} \mathrm{O}_{2}$ in the cardiomyocyte cell line $\mathrm{H} 9 \mathrm{c} 2$. These results suggested that overexpression of ISL1 might be a novel strategy for enhancing the efficacy of stem cell therapy.

IGFBPs are essential for the transport of insulin-like growth factors (IGFs), prolong their half-lives, and regulate the availability of free IGFs for interaction with IGF receptors, thereby modulating the effects of IGFs. Recent studies have provided ample evidence that IGFBPs have unique activities in addition to interactions with the IGF/IGF-IR (insulin resistance) axis [26]. In particular, IGF/IGF-IR-independent actions of IGFBP3 have been shown to 
contribute to the pathophysiology of a variety of human diseases, such as cancer, diabetes, and Alzheimer's disease [27]. IGFBP3 regulates the promitogenic and antiapoptotic functions of IGFs, but it also has independent functions [28]. IGFBP3 can enhance the proliferative effects of IGFs or inhibit IGF actions. In cell culture, IGFBP3 has also been shown to promote both apoptosis and survival. Granata et al. reported that IGFBP3 differentially regulates endothelial cell apoptosis through involvement of the sphingolipid signaling pathways. Moreover, the survival effect of IGFBP3 seems to be mediated by IGF-IR [29]. IGFBP3 positively regulates angiogenesis through involvement of IGF-IR signaling and subsequent sphingomyelin kinase (SphK) activation [30]. IGFBP3 upregulates IGF-1, a well-known anti-apoptotic and proangiogenic factor, activates IGF-IR and its downstream pathways phosphatidyl inositol-3 (PI3K), Akt, and mitogen-activated protein kinase (MAPK) extracellular signal-regulated kinase (ERK)1/2 [31]. However, the effect of IGFBP3 on cardiomyocyte apoptosis is not clear. In this study, we observed the apoptotic-related gene expression profiles of ISL1hMSCs and found high expression. We also observed a large difference in the fold-change of IGFBP3 between Ctrl-hMSCs and ISL1-hMSCs. The apoptotic effect of ISL1-hMSCs-CM was clearly reversed by the IGFBP3 neutralization antibody. These data suggest that IGFBP3 is an important anti-apoptotic paracrine factor that protects cardiomyocytes in ischemic hearts. We will explore additional molecular signaling mechanisms, such as IGF-IR, SphK activation, PI3K, Akt, or the MAPK signaling pathway in the future.

IGFBP3 has numerous functional roles, many of which are associated with the functional regulation of IGFs (IGF-dependent effects). Other major functional roles are related to their IGF-independent actions. The direct role of IGFBP3 binding is the target of ongoing research. Kazezian et al. described interferon-alpha signaling pathway activation with IFIT3 and IGFBP3 upregulation, which may affect cellular function in human degenerative discs [32]. IGFBP3 has been identified as the most strongly upregulated gene in degenerative human annulus fibrosis. The interferon-alpha signaling pathway is activated in the human degenerative annulus fibrosis via induction of 3 IFITs and other genes, such as IGFBP3. In contrast, $\mathrm{He}$ et al. found that activation of IGF-1/ IGFBP3 signaling by berberine improves the intestinal mucosal barrier in rats with acute endotoxemia [33]. Deng et al. reported that IGFBP3 is an important MSC homing molecule and reported on the therapeutic potential of hMSC extracellular matrix in bone regeneration [34]. In our study, overexpression of ISL1 in hMSCs promoted cell survival in a model of MI and enhanced their paracrine functions to protect cardiomyocytes, which might be completed through IGFBP3.
Our study provides new experimental evidence for the research of IGFBP3.

\section{Conclusions}

Overall, this study suggests that overexpression of ISL1 in hMSCs promoted cell survival in a model of MI and enhanced their paracrine function to protect cardiomyocytes, which may be mediated through IGFBP3. Overexpression of ISL1 could be a novel strategy for enhancing the efficacy of stem cell-mediated cardiac repair after MI.

\section{Additional files}

\section{Additional file 1: Table S1. GPCR primer information.}

Table S2. Sequencing data statistical results. Table S3. Alignment data statistical results. Table S4. Apoptosis-related secreted factors induced by Ctrl-hMSCs and ISL1-hMSCs. (PPTX $81 \mathrm{~kb}$ )

Additional file 2: Figure S1. Transplantation of ISL1-hMSCs improved cardiac function (LVEDV, LVESV and CO) in amyocardial infarction (MI) model. ${ }^{*} p<0.05$ vs. sham; ${ }^{\#} p<0.05$ vs. MI + PBS; ${ }^{\&} p<0.05$ vs. $\mathrm{MI}+$ ISL1-hMSCs. Figure S2. ISL1 overexpression reduced TUNEL-positive cardiomyocytes in infarct hearts. Scale bar $=50 \mu \mathrm{m}$. Figure S3. ISL1 overexpression reduced CD3+ T lymphocytes in infarct hearts. Scale bar $=50$ $\mu \mathrm{m}$. Figure S4. ISL1 overexpression reduced the number of CD68+ T lymphocytes in infarct hearts. Scale bar $=50 \mu \mathrm{m}$. Figure S5. ISL1 overexpression reduced inflammation cytokines TNFa, IL-6, and IL-10. Scale bar $=50 \mu \mathrm{m}$. Figure S6. ISL1 overexpression downregulated the proliferation and proinflammatory cytokine production of CD3+ T cells in vitro. ${ }^{*} p<$ 0.05 vs. control; $\#$ < 0.05 vs. Ctrl-hMSCs. Figure S7. Representative images and quantification of Bax, BCl-2, cleaved caspase 3, and full-length caspase 3 in ISL1-hMSCs and Ctrl-hMSCs with or without H2O2. ${ }^{*} p<0.05$ vs. $\mathrm{H} 2 \mathrm{O} 2+\mathrm{Ctrl}-\mathrm{hMSC}$. Figure S8. Top $10 \mathrm{GO}$ functions of upregulated (a) and downregulated (b) genes in ISL1-MSCs. Figure S9. Heat map display of secreted proteins with RPKM values of more than 100 in ISL1hMSCs and Ctrl-hMSCs. Figure S10. The IGFBP3 inhibition assay showed a reduction in active IGFBP3 in ISL1-hMSCs-CM. ${ }^{*} p<0.05$ vs. control; ${ }^{*} p<$ 0.05 vs. $\mathrm{H}_{2 \mathrm{O}}{ }_{;}{ }^{{ }^{*}} p<0.05$ vs. H2O2 + ISL1-hMSCs. Scale bar $=100 \mu \mathrm{m}$. Figure S11. The anti-apoptotic effect of IGFBP3 in ISL1-hMSCs-CM on the human cardiomyocyte cell line AC16 subjected to oxidative injury. Apoptosis rate $=$ (TUNEL positive nuclei / DAPI + nuclei) $\times 100 \% .{ }^{*} p<0.05$ vs. control; ${ }^{\sharp} p<0.05$ vs. H2O2; ${ }^{p} p<0.05$ vs. H2O2 + Ctrl-hMSCs; ${ }^{\circledR} p<0.05$ vs. H2O2 + ISL1-hMSCs. Scale bar $=100 \mu \mathrm{m}$. DAPI: 4',6- diamidino-2phenylindole. (PPT $15681 \mathrm{~kb})$

\section{Abbreviations}

CM: Conditioned medium; CO: Cardiac output; DAPI: 4'6-Diamidino-2phenylindole; DMEM: Dulbecco's modified Eagle's medium; EF: Ejection fraction; EF1a: Elongation factor 1a; ELISA: Enzyme-linked immunosorbent assay; FACS: Fluorescence-activated cell sorting; FBS: Fetal bovine serum; FITC: Fluorescein isothiocyanate; FS: Fractional shortening; GO: Gene Ontology; hMSC: Human mesenchymal stem cell; HNA: Human nuclear antigen; IFN: Interferon; IGF: Insulin-like growth factor; IGFBP3: Insulin-like growth factor binding protein 3; IL: Interleukin; IR: Insulin resistance; ISL1: Islet-1; LAD: Left anterior descending coronary artery; LVEDV: Left ventricular end-diastolic volume; LVESV: Left ventricular end-systolic volume; MI: Myocardial infarction; PBS: Phosphate-buffered saline; PCR: Polymerase chain reaction; PE: Phycoerythrin; PHD2: Prolyl hydroxylase domain protein 2; PI: Propidium iodide; qRT-PCR: Quantitative reverse-transcription polymerase chain reaction; SD: Standard deviation; TGF: Transforming growth factor; TNF: Tumor necrosis factor; TUNEL: Transferase-mediated deoxyuridine triphosphate-biotin nick end labeling

\section{Acknowledgments}

The authors would like to thank Dr. Wang Min, Yale University, for advice. We also thank Dr. Yangxin Chen and Dr. Yong Xie, Sun Yat-sen Memorial Hospital, for kindly supplying the human cardiomyocyte cell line AC16. 


\section{Funding}

This work was supported by the National Key Research and Development Program of China (2017YFA0103403 and 2017YFA0103802); the National Natural Science Foundation of China (81770494, 81570487, 81425016, and 81600400); the Frontier and Innovation of Key Technology Project in Science and Technology Department of Guangdong Province (2013B021800274, 2014B020225007, 2015B020229001, 2015B020228001, 2016B030229002, and 2017B020231001); the Guangdong Natural Science Foundation (2014A030310049, 2015A030313026, and 2017A030313877); the Key Scientific and Technological Program of Guangzhou City (201704020223, 2014 J4500031, 201510010024, and 201604020010); the Medical Research Foundation of Guangdong Province (B2013098); and The Fundamental Research Funds for Colleges and Universities (3161033, 17ykzd07).

\section{Availability of data and materials}

The datasets used and/or analyzed during the current study are available from the corresponding author on reasonable request.

\section{Authors' contributions}

QX carried out the cell and animal experiments and drafted the manuscript. $\mathrm{YL}$ carried out the flow cytometry assay. HC participated in the stem cell differentiation assay. WH participated in the RNA sequencing. JL carried out the animal model. HC carried out the Western blotting and ELISA assay. DH carried out the TUNEL assay and immunohistochemistry. ZZ participated in the GRT-PCR and intracellular cytokine staining. APX and WL conceived the study, participated in its design and coordination, and helped to draft the manuscript. All authors read and approved the final manuscript.

\section{Ethics approval}

All the animal experiments involved in this research have been approved by the Ethics Committee, Zhongshan School of Medicine, Sun Yat-sen University (reference number: 2013 No. 40). All experimental research on animals followed internationally recognized guidelines, the Declaration of Helsinki, and all guidelines in China.

\section{Consent for publication}

Not applicable.

\section{Competing interests}

The authors declare that they have no competing interests.

\section{Publisher's Note}

Springer Nature remains neutral with regard to jurisdictional claims in published maps and institutional affiliations.

\section{Author details \\ ${ }^{1}$ Center for Stem Cell Biology and Tissue Engineering, Key Laboratory for Stem Cells and Tissue Engineering, Ministry of Education, Sun Yat-sen University, Guangzhou, People's Republic of China. 'Zhongshan Medical School, Sun Yat-sen University, Guangzhou, People's Republic of China. ${ }^{3}$ Department of Cardiology, the Red Cross hospital of Guangzhou City, the Fourth Affiliated Hospital of Jinan University, Guangzhou, People's Republic of China. ${ }^{4}$ The First Affiliated Hospital, Sun Yat-sen University, Guangzhou, People's Republic of China. ${ }^{5}$ Sun Yat-sen Memorial Hospital, Sun Yat-sen University, Guangzhou, People's Republic of China.}

Received: 3 June 2017 Revised: 8 February 2018 Accepted: 8 February 2018 Published online: 26 February 2018

\section{References}

1. Christoffels V. Muscle for a damaged heart. Nature. 2011;474:585-6.

2. Wu JMF, Hsueh YC, Ch'ang HJ, Luo CY, Wu LW, Nakauchi H, Hsieh PCH. Circulating cells contribute to cardiomyocyte regeneration after injury. Circ Res. 2014;116:633-41.

3. Hensley MT, Tang J, Woodruff K, Defrancesco T, Tou S, Williams CM, Breen M, Meurs K, Keene B, Cheng K. Intracoronary allogeneic cardiospherederived stem cells are safe for use in dogs with dilated cardiomyopathy. J Cell Mol Med. 2017;21:1503-12.

4. Gnecchi M, He H, Melo LG, Noiseaux N, Morello F, Boer RA, Zhang L, Pratt RE, Dzau VJ, Ingwall JS. Early beneficial effects of bone marrow-derived mesenchymal stem cells overexpressing Akt on cardiac metabolism after myocardial infarction. Stem Cells. 2009;27:971-9.

5. Wang WE, Yang D, Li L, Wang W, Peng Y, Chen C, Chen P, Xia X, Wang H, Jiang J, Liao Q, Li Y, Xie G, Huang H, Guo Y, Ye L, Duan DD, Chen X, Houser $S R$, Zeng C. Prolyl hydroxylase domain protein 2 silencing enhances the survival and paracrine function of transplanted adipose-derived stem cells in infarcted myocardium. Circ Res. 2013;113:288-300.

6. Cai CL, Shi Y, Chu PH, Pfaff SL, Chen J, Evans S. IsI1 identifies a cardiac progenitor population that proliferates prior to differentiation and contributes a majority of cells to the heart. Dev Cell. 2003;5:877-89.

7. Abu-Issa R, Waldo K, Kirby ML. Heart fields: one, two or more? Dev Biol. 2004:272:281-5.

8. Laugwitz KL, Lam J, Gruber P, Chen Y, Woodard S, Lin LZ, Cai CL, Lu MM, Reth M, Platoshyn O, Yuan JX, Evans S, Chien KR. Postnatal isl1+ cardioblasts enter fully differentiated cardiomyocyte lineages. Nature. 2005;433:647-53.

9. Cagavi E, Suh CY, Sun B, Yue Z, Jiang Z, Yue L, Qyang Y. Functional cardiomyocytes derived from Isl1 cardiac progenitors via Bmp4 stimulation. PLoS One. 2014;9:e110752.

10. Liu J, Li W, Wang Y, Fan W, Li P, Lin W, Yang D, Fang R, Feng M, Hu C, Du Z, Wu G, Xiang AP. Islet-1 overexpression in human mesenchymal stem cells promotes vascularization through monocyte chemoattractant protein-3. Stem Cells. 2014;32:1843-54.

11. Xie Y, Gu ZJ, Wu MX, Huang TC, Ou JS, Ni HS, Lin MH, Yuan WL, Wang JF, Chen YX. Disruption of calcium homeostasis by cardiac-specific overexpression of PPAR- $\gamma$ in mice: a role in ventricular arrhythmia. Life Sci. 2016; 167:12-21.

12. Huang YZ, Cai JQ, Lv FJ, Xie HL, Yang ZM, Huang YC, Deng L. Species variation in the spontaneous calcification of bone marrow-derived mesenchymal stem cells. Cytotherapy. 2013;15:323-9.

13. Cai D. BDNF-mediated enhancement of inflammation and injury in the aging heart. Physiol Genomics. 2005;24:191-7.

14. Xiang Q, Hong D, Liao Y, Cao Y, Liu M, Pang J, Zhou J, Wang G, Yang R, Wang W, Xiang AP. Overexpression of Gremlin1 in mesenchymal stem cells improves hindlimb ischemia in mice by enhancing cell survival. J Cell Physiol. 2017;232:996-1007.

15. Forte G, Pietronave S, Nardone G, Zamperone A, Magnani E, Pagliari S, Pagliari F, Giacinti C, Nicoletti C, Musaró A, Rinaldi M, Ribezzo M, Comoglio C, Traversa E, Okano T, Minieri M, Prat M, Di Nardo P. Human cardiac progenitor cell grafts as unrestricted source of supernumerary cardiac cells in healthy murine hearts. Stem Cells. 2011;29:2051-61.

16. Bai X, Yan Y, Coleman M, Wu G, Rabinovich B, Seidensticker M, Alt E. Tracking long-term survival of intramyocardially delivered human adipose tissue-derived stem cells using bioluminescence imaging. Mol Imaging Biol. 2010;13:633-45.

17. Pfaff SL, Mendelsohn M, Stewart CL, Edlund T, Jessell TM. Requirement for LIM homeobox gene IsI1 in motor neuron generation reveals a motor neuron-dependent step in interneuron differentiation. Cell. 1996;84:309-20.

18. Moretti A, Caron L, Nakano A, Lam JT, Bernshausen A, Chen Y, Qyang Y, Bu L, Sasaki M, Martin-Puig S, Sun Y, Evans SM, Laugwitz KL, Chien KR. Multipotent embryonic is $11+$ progenitor cells lead to cardiac, smooth muscle, and endothelial cell diversification. Cell. 2006;127:1151-65.

19. Yi Q, Xu H, Yang K, Wang Y, Tan B, Tian J, Zhu J. Islet-1 induces the differentiation of mesenchymal stem cells into cardiomyocyte-like cells through the regulation of Gcn5 and DNMT-1. Mol Med Rep. 2017;15:2511-20.

20. Barzelay A, Hochhauser E, Entin-Meer M, Chepurko Y, Birk E, Afek A, Barshack I, Pinhas L, Rivo Y, Ben-Shoshan J, Maysel-Auslender S, Keren G, George J. Islet-1 gene delivery improves myocardial performance after experimental infarction. Atherosclerosis. 2012;223:284-90.

21. Li Y, Lei L, Liu L, Ma P, Wang Z. Transplantation of multipotent Is|1+ cardiac progenitor cells preserves infarcted heart function in mice. Am J Transl Res. 2017;9:1530-42.

22. Zeng L, Hu Q, Wang X, Mansoor A, Lee J, Feygin J, Zhang G, Suntharalingam P, Boozer S, Mhashilkar A, Panetta CJ, Swingen C, Deans R, From AH, Bache RJ, Verfaillie CM, Zhang J. Bioenergetic and functional consequences of bone marrow-derived multipotent progenitor cell transplantation in hearts with postinfarction left ventricular remodeling. Circulation. 2017;115:1866-75.

23. Laflamme MA, Chen KY, Naumova AV, Muskheli V, Fugate JA, Dupras SK, Reinecke H, Xu C, Hassanipour M, Police S, O'Sullivan C, Collins L, Chen Y, Minami E, Gill EA, Ueno S, Yuan C, Gold J, Murry CE. Cardiomyocytes derived from human embryonic stem cells in pro-survival factors enhance function of infarcted rat hearts. Nat Biotechnol. 2007;25:1015-24. 
24. Heldman AW, DF DL, Fishman JE, Zambrano JP, Trachtenberg BH, Karantalis V, Mushtaq M, Williams AR, Suncion VY, IK MN, Ghersin E, Soto V, Lopera G, Miki R, Willens H, Hendel R, Mitrani R, Pattany P, Feigenbaum G, Oskouei B, Byrnes J, Lowery MH, Sierra J, Pujol MV, Delgado C, Gonzalez PJ, Rodriguez JE, Bagno LL, Rouy D, Altman P, Foo CW, da Silva J, Anderson E, Schwarz R, Mendizabal A, Hare JM. Transendocardial mesenchymal stem cells and mononuclear bone marrow cells for ischemic cardiomyopathy: the TAC-HFT randomized trial. JAMA. 2014;311:62-73.

25. Lane SW, Williams DA, Watt FM. Modulating the stem cell niche for tissue regeneration. Nat Biotechnol. 2014;32:795-803.

26. Lee YC, Jogie-Brahim S, Lee DY, Han J, Harada A, Murphy LJ, Oh Y. Insulinlike growth factor-binding protein-3 (IGFBP-3) blocks the effects of asthma by negatively regulating NF-KB signaling through IGFBP-3R-mediated activation of caspases. J Biol Chem. 2011;286:17898-909.

27. Lofqvist C, Chen J, Connor KM, Smith ACH, Aderman CM, Liu N, Pintar JE, Ludwig T, Hellstrom A, Smith LEH. IGFBP3 suppresses retinopathy through suppression of oxygen-induced vessel loss and promotion of vascular regrowth. Proc Natl Acad Sci U S A. 2007;104:10589-94.

28. Mohan S, Baylink DJ. IGF-binding proteins are multifunctional and act via IGFdependent and -independent mechanisms. J Endocrinol. 2002;175:19-31.

29. Granata R, Trovato L, Garbarino G, Taliano M, Ponti R, Sala G, Ghidoni R, Ghigo E. Dual effects of IGFBP-3 on endothelial cell apoptosis and survival: involvement of the sphingolipid signaling pathways. FASEB J. 2004;18:1456-8.

30. Granata LTR, Lupia E, Sala G, Settanni F, Camussi G, Ghidoni R, Ghigo E. Insulinlike growth factor binding protein-3 induces angiogenesis through IGF-I- and SphK1-dependent mechanisms. J Thromb Haemost. 2007:5:835-45.

31. Lopez-Lopez C, LeRoith D, Torres-Aleman I. Insulin-like growth factor I is required for vessel remodeling in the adult brain. Proc Natl Acad Sci U S A. 2004;101:9833-8.

32. Kazezian Z, Gawri R, Haglund L, Ouellet J, Mwale F, Tarrant F, O'Gaora P, Pandit A, Alini M, Grad S. Gene expression profiling identifies interferon signalling molecules and IGFBP3 in human degenerative annulus fibrosus. Sci Rep. 2015;5:15662.

33. He Y, Yuan X, Zhou G, Feng A. Activation of IGF-1/IGFBP-3 signaling by berberine improves intestinal mucosal barrier of rats with acute endotoxemia. Fitoterapia. 2018;124:200-5.

34. Deng M, Luo K, Hou T, Luo F, Xie Z, Zhang Z, Yang A, Yu B, Yi S, Jiulin T, Dong $\mathrm{S}$, Xu J. IGFBP3 deposited in the human umbilical cord mesenchymal stem cell-secreted extracellular matrix promotes bone formation. J Cell Physiol. 2017; https://doi.org/10.1002/jcp.26342. [Epub ahead of print]

\section{Submit your next manuscript to BioMed Central and we will help you at every step:}

- We accept pre-submission inquiries

- Our selector tool helps you to find the most relevant journal

- We provide round the clock customer support

- Convenient online submission

- Thorough peer review

- Inclusion in PubMed and all major indexing services

- Maximum visibility for your research

Submit your manuscript at www.biomedcentral.com/submit
Biomed Central 